\title{
Effect of cooling fluids on high frequency electric and magnetic fields in microelectronic systems with integrated TSVs
}

\author{
Abas Abdoli*, Sohail R. Reddy, George S. Dulikravich, S.M. Javad Zeidi \\ Department of Mechanical and Materials Engineering, MAIDROC Laboratory, Florida International University, 10555 West Flagler Street, Miami, FL 33174, USA
}

\section{A R T I C L E I N F O}

\section{Keywords:}

Electronics cooling

Integrated TSV

Electromagnetic field

Electro-magneto fluid dynamics

\begin{abstract}
A B S T R A C T
A fully 3D conjugate numerical analysis was performed to reveal the effects of air, R134a refrigerant and water on electromagnetic fields of electronic cooling designs made of arrays of micro pin-fins with integrated ThroughSilicon-Vias (TSVs). The integrated TSV cooling configuration included 8 cylindrical TSVs with $150 \mu \mathrm{m}$ diameter each and $200 \mu \mathrm{m}$ height. The external dimensions of the silicon substrate were $900 \times 700 \times 280 \mu \mathrm{m}$. Each TSV encapsulated four equally spaced copper vias each having a diameter of $40 \mu \mathrm{m}$. The impacts of the presence of the stationary cooling fluids without heat transfer on TSVs electric and magnetic fields were examined for five different frequencies; $100 \mathrm{MHz}, 500 \mathrm{MHz}, 1 \mathrm{GHz}, 5 \mathrm{GHz}$ and $10 \mathrm{GHz}$. Then, separately, the effects of moving cooling water with temperature-dependent physical properties were studied while exposing the cooled micro pin-fin array to a uniform heat flux of $500 \mathrm{~W} \mathrm{~cm}^{-2}$. For the case of stagnant and moving cooling fluids it was found that water influences the electric field twice as much as either R134a or air and that this influence decreases only negligibly with the increase in frequency of the electric current passing through the TSVs. The influence of the presence of the stagnant and moving cooling fluids on the magnetic field is orders of magnitude smaller and reduces rapidly with the increased frequency.
\end{abstract}

\section{Introduction}

Thermal management challenges facing electronic cooling developers $[1,2]$ are currently at the confluence of chip power dissipation well above $100 \mathrm{~W} \mathrm{~cm}^{-2}$ as background heat flux, and localized hot spots with more than $1000 \mathrm{~W} \mathrm{~cm}^{-2}$ fluxes. Several approaches were proposed for cooling such high power chips with multiple hot spots, which has opened a door for new hyper integrated smart systems [3]. In this paper, we will focus on the micro-electronic forced convection cooling concept that uses arrays of micro pin-fins representing Through Silicon Vias (TSVs) [4]. Three-dimensional TSV-based integration has shown very promising results in terms of performance, functionality and power consumption in electronic packaging. In a recent study, Abdoli et al. [5] performed 3D thermo-fluid-stress analyses using different shapes for TSV cross sections to improve the heat transfer and reduce required pumping power. Later, Reddy et al. [6] applied multi-objective optimization techniques to find the optimal micro pinfin cooling configurations for high heat flux chips with a hot spot.

One of the interesting phenomena occurring in this type of cooling systems, and yet to be studied, is the interaction between the electric, magnetic, thermal and pressure fields involved. Savidis et al. [7], He and Lu [8], Xie and Swaminathan [9], He et al. [10] and Xie et al. [11] investigated voltage drops in power delivery network for TSV-based 3D integration packages. It is well understood that electric fields and magnetic fields can influence the flow-field and consequently the heat transfer [12]. This area has been well researched and is known as electro-magneto-fluid dynamics [13].

An even more intriguing issue is the answer to a potentially important question: is it possible for the cooling fluid and its flow-field and temperature field to influence the imposed high frequency electric and magnetic fields in the TSVs? This possible "reverse" interaction is especially intriguing for very small systems such as micro-electronics cooling where the electric and magnetic signals transmitted through TSVs should not be altered by any possible electric and magnetic fields induced by the either stationary or moving and temperature-dependent cooling fluid. Xei et al. [11] performed an electrical-thermal modeling of TSV arrays in case of pure conduction with no cooling fluid involved. They reported that the temperature dependency of material properties such as the silicon conductivity cannot be neglected for TSV array design. At least in the case of 2D magnetohydrodynamic flows, it was shown analytically that such "reverse" interaction is possible when electric conductivity of the cooling fluid is temperature-dependent $[14,15]$.

The aim of this paper is to address the question of sensitivity and magnitude of such "reverse" influence of the various common stagnant

\footnotetext{
* Corresponding author.

E-mail addresses: aabdo004@fiu.edu (A. Abdoli), sredd001@fiu.edu (S.R. Reddy), dulikrav@fiu.edu (G.S. Dulikravich), szeid001@fiu.edu (S.M.J. Zeidi).
} 


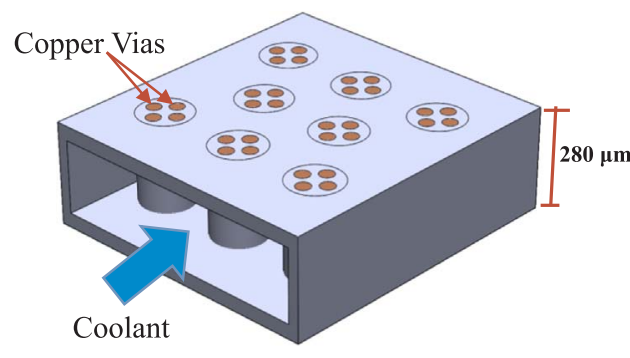

a)

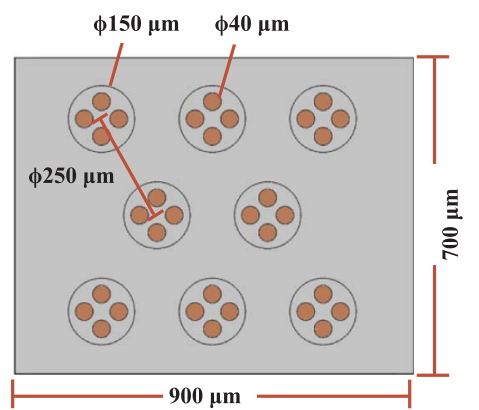

b)

Fig. 1. Single stack cooling design with integrated TSVs, a) 3D view, b) top view with dimensions.

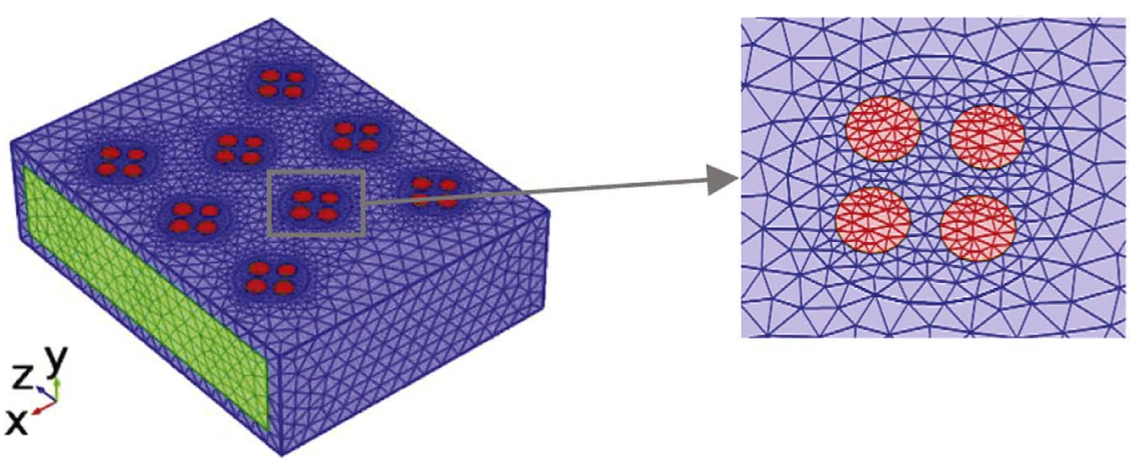

Fig. 2. Hybrid computational grid with an enlarged view of a single TSV and the four imbedded vias.

and moving cooling fluids on the applied electric and magnetic fields passing through the TSVs. The answers will be found by performing fully conjugate three-dimensional numerical simulations using an elementary electro-magneto-hydro-dynamics model based on the Navier-Stokes equations and Maxwell equations. Impacts of three different fluids (air, R134a liquid refrigerant and water) on electric and magnetic fields of TSV-based electronic integration packages were investigated for five different frequencies of the electric and magnetic fields in the range between $100 \mathrm{MHz}$ and $10 \mathrm{GHz}$.

\section{Design and methodology}

A single stack cooling system with 8 integrated micro pin-fins (Fig. 1) was virtually designed for numerical simulations. Silicon was used for the substrate material and the micro pin-fins.

Fig. 1a illustrates all micro pin-fins and copper vias arrangements on the array with dimension of $900 \mu \mathrm{m} \times 700 \mu \mathrm{m}$ (Fig. 1b). As this figure depicts, total height of silicon substrates was $280 \mu \mathrm{m}$. Fig. 1b shows the spacing between the micro pin-fins, and diameters of micro pin-fins and copper vias.

Maxwell's equations were the governing equations for multi-domain electromagnetic simulations

$\nabla \cdot D=\rho$

$\nabla \times E=-\frac{\partial B}{\partial t}$

$\nabla . B=0$

$\nabla \times H=J+\frac{\partial D}{\partial t}$

Here, $\rho$ is the electric charge density, $E$ is the electric field, $D$ is the electric displacement field, $J$ is the electric current, $B$ is the magnetic field and $H$ is the magnetic flux density. To solve these equations, material constitutive relations are required which relate electric field $(E)$ to electric displacement field $(D)$, current $(J)$ to electric field $(E)$, and magnetic field $(B)$ to magnetic flux density $(H)$.

The applied electric field and magnetic field frequencies in the range of $100 \mathrm{MHz}$ and $10 \mathrm{GHz}$ correspond to wavelengths between $3 \mathrm{~cm}$ and $3 \mu \mathrm{m}$ in vacuum. Therefore, the AC/DC analysis module in COMSOL Multiphysics software [16] was the proper module to use for simulations. This module integrates the frequency domain form of the magnetic fields interface, as follow

$\nabla \times \mu^{-1}(\nabla \times A)+\left(j \omega \sigma-\omega^{2} \varepsilon\right) A=J_{s}$

Here, $\mu$ is magnetic permeability, $\varepsilon$ is electric permittivity, $\omega$ is frequency, $\sigma$ is electric conductivity, $A$ is magnetic vector potential, $J_{s}$ is the source current. The following equations are solved for the electric field and induced current

$E=j \omega A$

$J_{i}=\sigma E$

Here, $J_{i}$ is the induced current. In order to integrate the Eqs. (1) through (5) using finite element technique, all solution domains have to be discretized spatially and temporally. Fig. 2 illustrates the hybrid computational grid generated by the COMSOL Multiphysics software. Fig. 2 (left) shows the grid in the entire solution domains. Fig. 2 (right) shows an enlarged view of the grid inside and around one of the silicon pin-fins with four imbedded copper vias. Total number of degrees of freedom for each of the analysis computations was 4233637.

$\mathrm{He}$ and Lu [8] studied the voltage drop for different number of TSVs. They reported around $2.5 \mathrm{mV}$ voltage drop for $4 \mathrm{TSVs}$ and $1 \mathrm{mV}$ voltage drop for 8 TSVs. They showed that voltage drop decreases by increasing the number of TSVs up to 16 TSVs. They did not take into account the effects of the cooling fluid.

In this paper, voltage drop of $1 \mathrm{mV}$ was assumed for copper vias. The direction of voltage drop was set in the opposite of y-axis. The rest of boundary surfaces were assumed to be electric insulators. In the following sections, results of fully 3D conjugate numerical simulations for each of the three fluids are presented separately. 
Table 1

Electromagnetic properties of silicon, copper and air used in Case 1.

\begin{tabular}{llll}
\hline Property & $\begin{array}{l}\text { Electric conductivity (S } \\
\mathrm{m}^{-1} \text { ) }\end{array}$ & $\begin{array}{l}\text { Relative } \\
\text { permittivity }\end{array}$ & $\begin{array}{l}\text { Relative } \\
\text { permeability }\end{array}$ \\
\hline Silicon & $1.56 \mathrm{e}-3$ & 11.7 & 1 \\
Copper & $5.998 \mathrm{e} 7$ & 1 & 1 \\
Air & $3.0 \mathrm{e}-15$ & 1 & 1 \\
\hline
\end{tabular}

\section{Case 1: stagnant air effect on electromagnetic fields}

In the first case, air was used as cooling fluid between TSVs. The electromagnetic properties such as electric conductivity, relative permittivity and relative permeability are required for each domain. It was assumed that the electromagnetic properties of silicon, copper and air were constant for all five frequencies. Table 1 shows the electromagnetic properties of silicon, copper and air.

Fig. 3 shows electric and magnetic field magnitude distributions for $100 \mathrm{MHz}$. Fig. 3a illustrates the electric field magnitude distribution in all eight TSVs and copper vias. Arrows indicate directions of electric field in the entire domain. As this figure demonstrates, the maximum magnitude of the electric field occurred at the top (and bottom) surface of silicon near the copper vias of those TSVs which were located at the corners. The maximum magnitude of the electric field was $6.264 \mathrm{~V} \mathrm{~m}^{-1}$. Larger electric field magnitudes at the corner TSVs are due to the fact that in these regions electric field can be scattered in silicon without any suppression.

For the two TSVs in the middle, electromagnetic fields were suppressed by each other due to their opposite directions. Fig. 3b shows the electric field around one of the middle TSVs. As this figure illustrates, the maximum value of electric field in this TSV was
$2.135 \mathrm{~V} \mathrm{~m}^{-1}$, which was around 3 times less than the global maximum. Distribution of electric field magnitude of one of the corner TSVs is shown in Fig. 3c. Larger electric field can be seen at both ends of this TSV near copper vias. Fig. 3d shows the top view of magnetic field magnitude with normalized directional arrows. From the direction of these arrows it can be observed that magnetic fields of middle TSVs were in opposite directions. Thus, they suppressed each other and resulted in a smaller magnetic field in this region. It should be also mentioned that the maximum value of the magnetic field by itself was very small, $1.225 \times 10^{-4} \mathrm{~T}$.

For further investigation of results, a sample line (orange line in Fig. 3d) was chosen to plot simulation results for all five frequencies. The sample line was located on the top surface of silicon $(y=280 \mu \mathrm{m})$.

Fig. 4a shows the electric field magnitude at this line. As this figure illustrates, electric field magnitudes at all different frequencies were almost the same. This indicates that changing the frequency did not affect the electric field magnitude at the sample line.

The magnetic field magnitudes for the same sample line are shown in Fig. 4b. It can be seen that by increasing the frequency, the magnetic field suppresses and tends to zero. This observation can be explained by the "skin effect" which causes the effective resistance of the copper via (conductor) to increase at higher frequencies where the skin depth is smaller, thus reducing the electric current and magnetic field magnitude.

\section{Case 2: stagnant r134a refrigerant effect on electromagnetic fields}

In Case 2, stagnant R134a refrigeration liquid, which is one of the most popular coolants, was used as the working fluid for the cooling system. Due to the lack of experimental data, the electromagnetic properties of R134a were assumed to be constant for all five frequen-

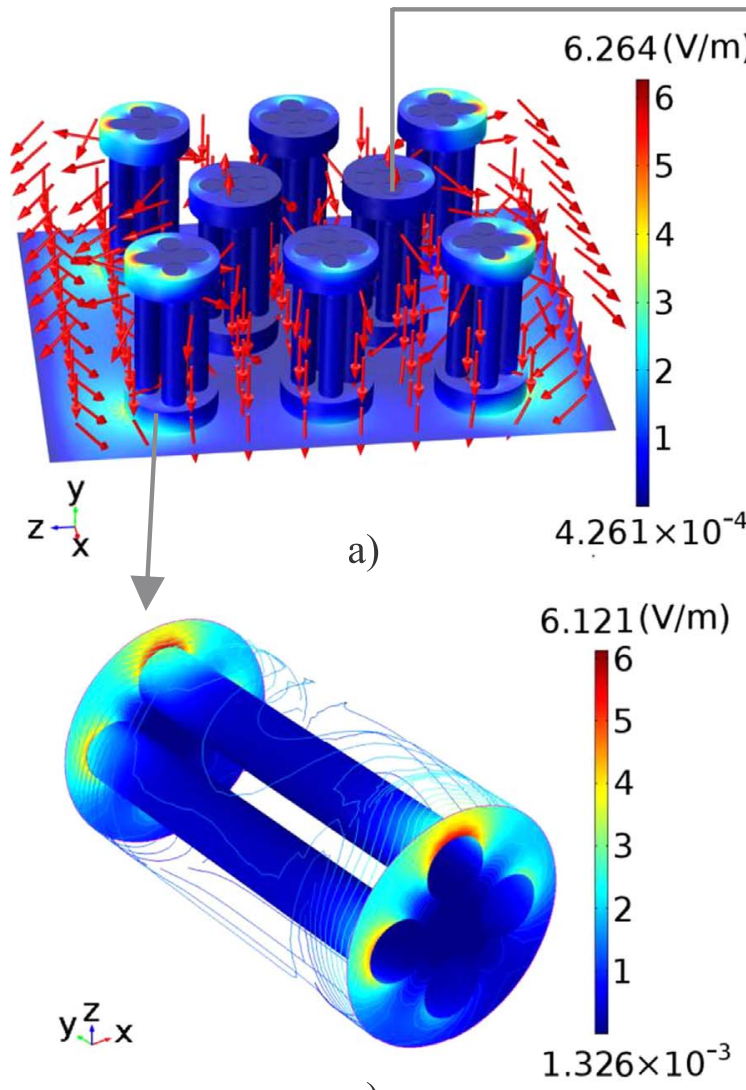

c)

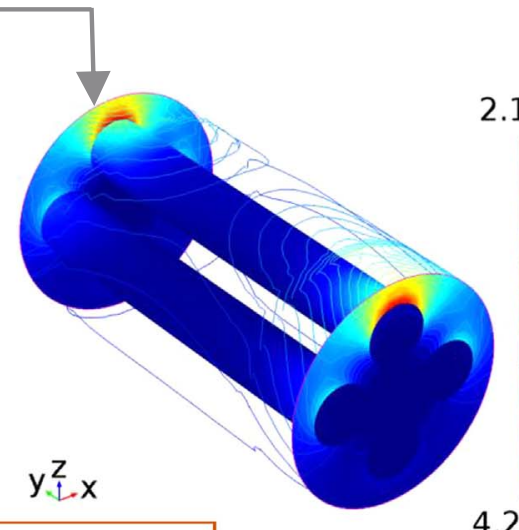

b)
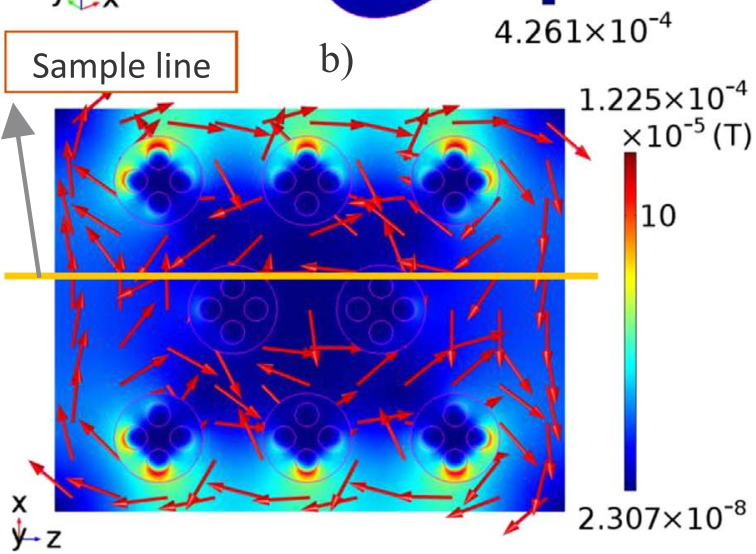

d)

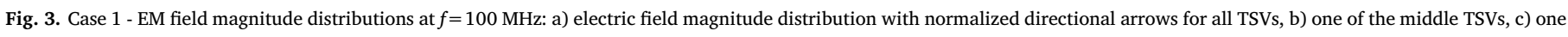

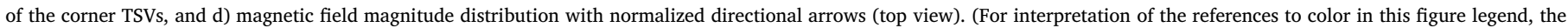
reader is referred to the web version of this article). 


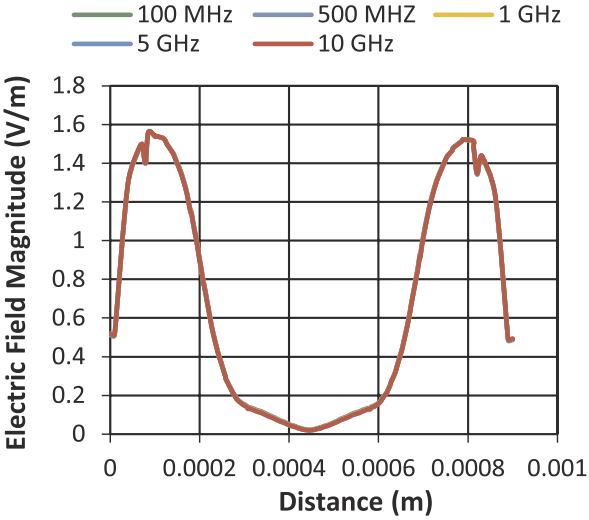

a)

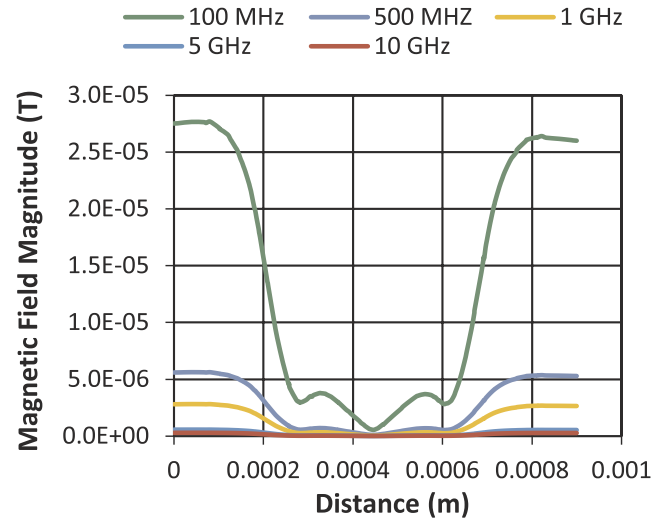

b)

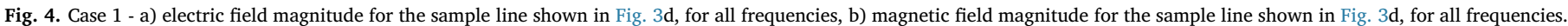

cies. Electric conductivity of R134a was assumed to be $4.17 \times 10^{-9} \mathrm{~S} \mathrm{~m}^{-1}[17,18]$, while its relative permittivity and relative permeability were set as constants and equal to 9.1 and 1.0 , respectively [19].

Electric and magnetic field magnitude distributions for $100 \mathrm{MHz}$ are shown in Fig. 5. As Fig. 5a indicates, the maximum value of the electric field in this case was $7.573 \mathrm{~V} \mathrm{~m}^{-1}$. The same distribution pattern for the electric field magnitude can be seen compared to Case 1 (Fig. 3a). Figs. $5 \mathrm{~b}$ and $5 \mathrm{c}$ show that the maximum values of electric fields in the middle TSV and corner TSV in Case 2 were $2.663 \mathrm{~V} \mathrm{~m}^{-1}$ and $7.421 \mathrm{~V} \mathrm{~m}^{-1}$, respectively. Larger electric field magnitudes can be observed (Fig. 5c) at both ends of this TSV compared to the same
TSV in Case 1 (Fig. 3c). For magnetic field, results were almost the same as in Case 1. One of the reasons for such similarity was the relative permeability values which were the same in both cases.

Electric and magnetic field magnitudes for the same sample line (Fig. 3d) are shown in Fig. 6. As Fig. 6a depicts, different graphs were obtained for the electric field magnitudes on the sample line.

The maximum value of the electric field was slightly increased from $1.56 \mathrm{~V} \mathrm{~m}^{-1}$ to $1.65 \mathrm{~V} \mathrm{~m}^{-1}$. By comparing Fig. 6a with Fig. 4a, two extra local minima can be detected near the centerline $(x=300 \mu \mathrm{m}$ and $\mathrm{x}=600 \mu \mathrm{m}$ ) in this figure. As Fig. $6 \mathrm{~b}$ shows, very similar results were obtained for magnetic field magnitude on the sample line for Case 2 (Fig. 6b) compared to Case 1 (Fig. 4b).

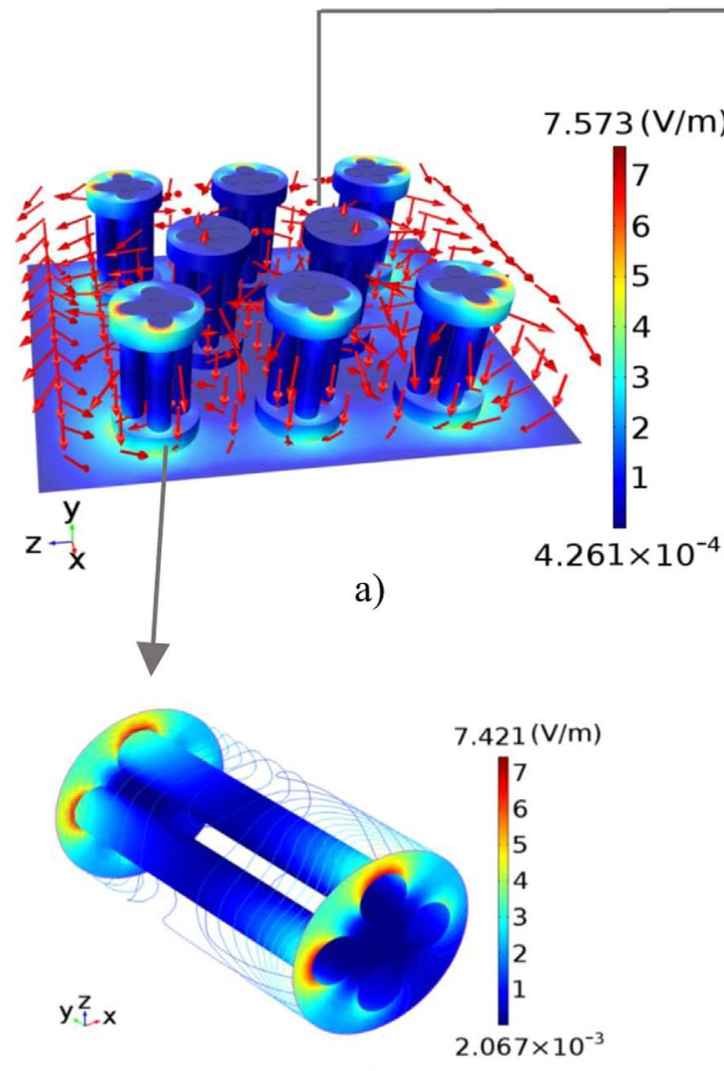

c)

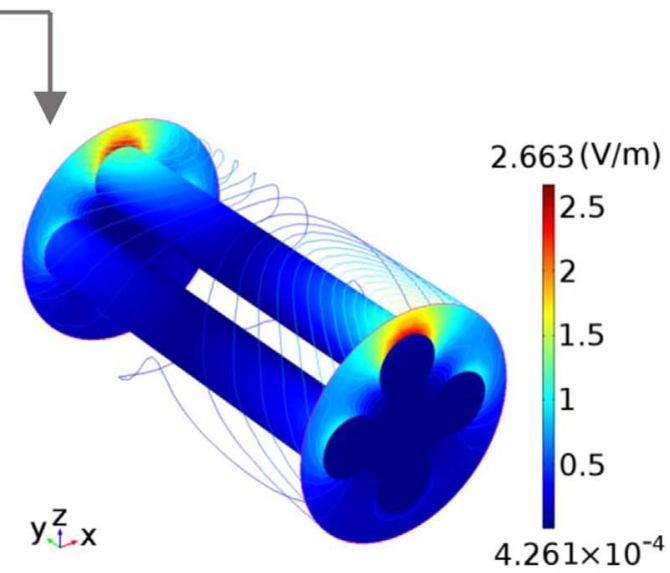

b)

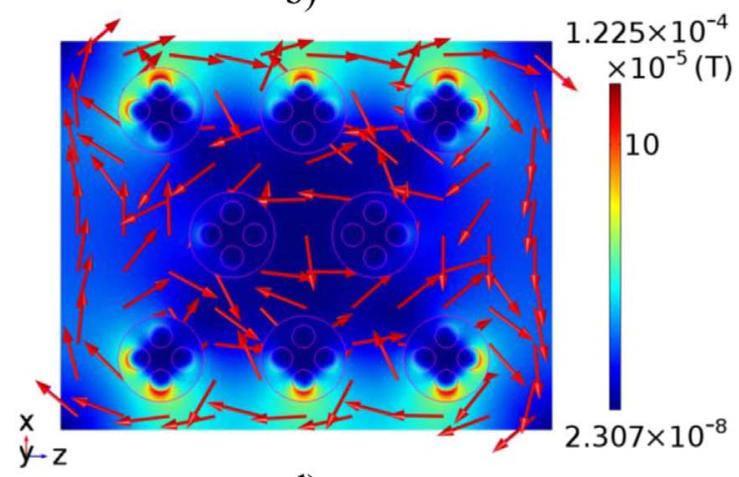

d)

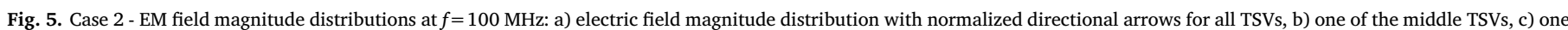
of the corner TSVs, and d) magnetic field magnitude distribution with normalized directional arrows (top view). 


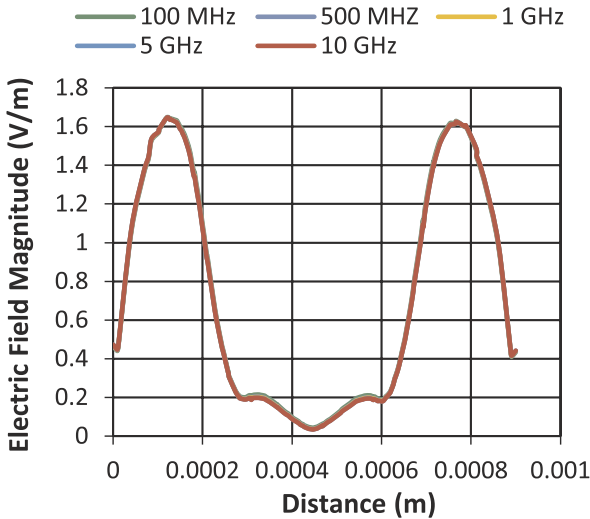

a)

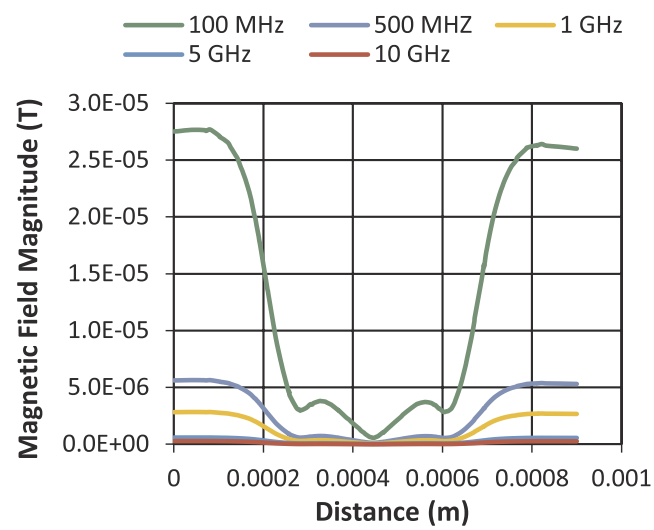

b)

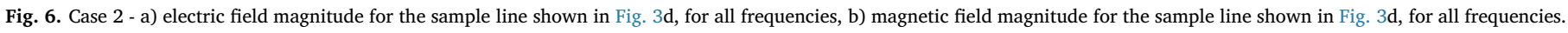

\section{Case 3: stagnant water effect on electromagnetic fields}

In the third case study, effects of stagnant water on TSVs electromagnetic field were simulated. Electric conductivity of water was assumed to be constant and equal to $5.5 \times 10^{-6} \mathrm{~S} \mathrm{~m}^{-1}$. Also, the value of relative permeability was considered to be constant and equal to 1 . Table 2 shows different values for relative permittivity for different frequencies. It can be observed that by increasing the frequency, the relative permittivity of water decreases.

The electric and magnetic field results for $100 \mathrm{MHz}$ are shown in Fig. 7. Fig. 7a shows the maximum of electric field magnitude was increased to $11.055 \mathrm{~V} \mathrm{~m}^{-1}$. Same distribution pattern in terms of local direction of the electric field can be observed compared to previous cases. Figs. $7 \mathrm{~b}$ and $7 \mathrm{c}$ illustrate larger electric field magnitudes at both ends of the TSVs compared to Case 1 and Case 2. However, as Fig. $7 d$ shows, the magnitude and distribution of magnetic field remained almost the same as in previous cases.

For better comparison, results of electromagnetic field magnitudes for the same sample line (Fig. 3d) are shown in Fig. 8. Larger variations in electric field magnitude can be observed for $100 \mathrm{MHz}, 500 \mathrm{MHz}$, $1 \mathrm{GHz}$ and $5 \mathrm{GHz}$ compared to Case 1 and Case 2. The magnitude of electric field for $10 \mathrm{GHz}$ has larger variations with respect to other frequencies. This is due to the large difference between the relative permittivity of water at this frequency compared to other four frequencies (Table 2). The same results were obtained for magnetic field magnitudes in Case 3 as those in Case 1 and Case 2.

6. Case 4: flowing cooling water effect on electromagnetic fields with strong heat transfer and temperature-dependent relative permittivity

In the three cases presented thus far, the cooling fluid was assumed to be stationary (stagnant) having either constant or temperaturedependent properties. In actual applications of the arrays of micro pinfins with integrated TSV, the cooling fluid is moving and features nonuniform temperature distribution. To incorporate this into the model, a fully three-dimensional conjugate heat transfer numerical analysis was performed using COMSOL software [16] by utilizing Navier-Stokes equations and Maxwell equations to acquire the compatible 3D flowfield and temperature distribution. An average coolant speed of $1 \mathrm{~m} \mathrm{~s}^{-1}$ was applied at the inlet and an absolute pressure of $120 \mathrm{kPa}$ was

Table 2

Relative permittivity of water at different frequencies $\left(T=30^{\circ} \mathrm{C}\right),[20,21]$ used in Case 3.

\begin{tabular}{llllll}
\hline Frequency & $100 \mathrm{MHz}$ & $500 \mathrm{MHz}$ & $1 \mathrm{GHz}$ & $5 \mathrm{GHz}$ & $10 \mathrm{GHz}$ \\
\hline Relative permittivity & 77 & 77 & 77 & 73 & 64 \\
\hline
\end{tabular}

applied at the outlet. A uniform heat flux of $350 \mathrm{~W} \mathrm{~cm}^{-2}$ was imposed on the top surface of the configuration $[5,6]$, while all other sides were thermally insulated. Temperature of the liquid coolant (pure water) at inlet was $30^{\circ} \mathrm{C}$.

The relative electric permittivity in previous test cases was assumed to be constant. However, electric permittivity is known to become frequency dependent above approximately $f=1000 \mathrm{~Hz}$ when it becomes a complex number that has a real part and an imaginary part. Moreover, the relative electric permittivity is a function of not only the frequency of the applied electric field, but also a function of temperature and electric conductivity. For some fluids in certain ranges of frequencies and in certain ranges of temperature the magnitude of the imaginary part is negligible, while in other frequency and temperature ranges for the same fluid the magnitude of the imaginary part is significant in comparison with the real part.

In Case 4, which involves moving coolant (pure water) and strong heat transfer, the electric conductivity of water was calculated as a function of temperature shown in Fig. 10 [22].

In Case 4, relative electric permittivity of water was modeled as a temperature-salinity-frequency dependent physical property by using an analytical model developed by Meissner and Wentz [23].

$$
\begin{aligned}
\varepsilon_{r}(T, S)= & \frac{\varepsilon_{S}(T, S)-\varepsilon_{1}(T, S)}{1+i \frac{v}{v_{1}(T, S)}}+\frac{\varepsilon_{1}(T, S)-\varepsilon_{\infty}(T, S)}{1+i \frac{v}{v_{2}(T, S)}}+\varepsilon_{\infty}(T, S) \\
& -i \frac{\sigma(T, S)}{\left(2 \pi \varepsilon_{0}\right) v}
\end{aligned}
$$

In Eq. (8), $\varepsilon_{r}$ is the relative electric permittivity of water as a function of temperature, T, and salinity, S. Here, $\varepsilon_{s}$ is the static (zero frequency) dielectric constant; $\varepsilon_{\infty}$ is dielectric constant at infinite frequencies, and can be considered constant in Klein-Swift model, while $\sigma(T, S)$ is the temperature and salinity dependent electric conductivity $\left[\mathrm{S} \mathrm{m}^{-1}\right]$. Finally, $\frac{1}{2 \pi \varepsilon_{0}}=17.97510 \mathrm{GHz} S \mathrm{~m}^{-1}$ in which $\varepsilon_{0}$ is the vacuum electric permittivity, $v_{1}(T, S=0)$ and $v_{2}(T, S=0)$ are the first and second order Debye relaxation factors, and $v$ is frequency of the imposed electric field given in GHz.

Eq. (8) shows real and imaginary parts of relative electric permittivity. In this study, since the water we use had no salinity, we consider $S$ to be zero. Analytic expressions for other parameters are [23]:

$\varepsilon_{s}(T, S=0)=\frac{3.70886 \times 10^{4}-8.2168 \times 10 T}{4.21854 \times 10^{2}+T}$

$\varepsilon_{1}(\mathrm{~T}, \mathrm{~S}=0)=\mathrm{a}_{0}+\mathrm{a}_{1} \mathrm{~T}+\mathrm{a}_{2} \mathrm{~T}^{2}$

$\mathrm{v}_{1}(\mathrm{~T}, \mathrm{~S}=0)=\frac{45+\mathrm{T}}{\mathrm{a}_{1}+\mathrm{a}_{2} \mathrm{~T}+\mathrm{a}_{3} \mathrm{~T}^{2}}$

$\varepsilon_{\infty}(\mathrm{T}, \mathrm{S})=\mathrm{a}_{6}+\mathrm{a}_{7} \mathrm{~T}$ 


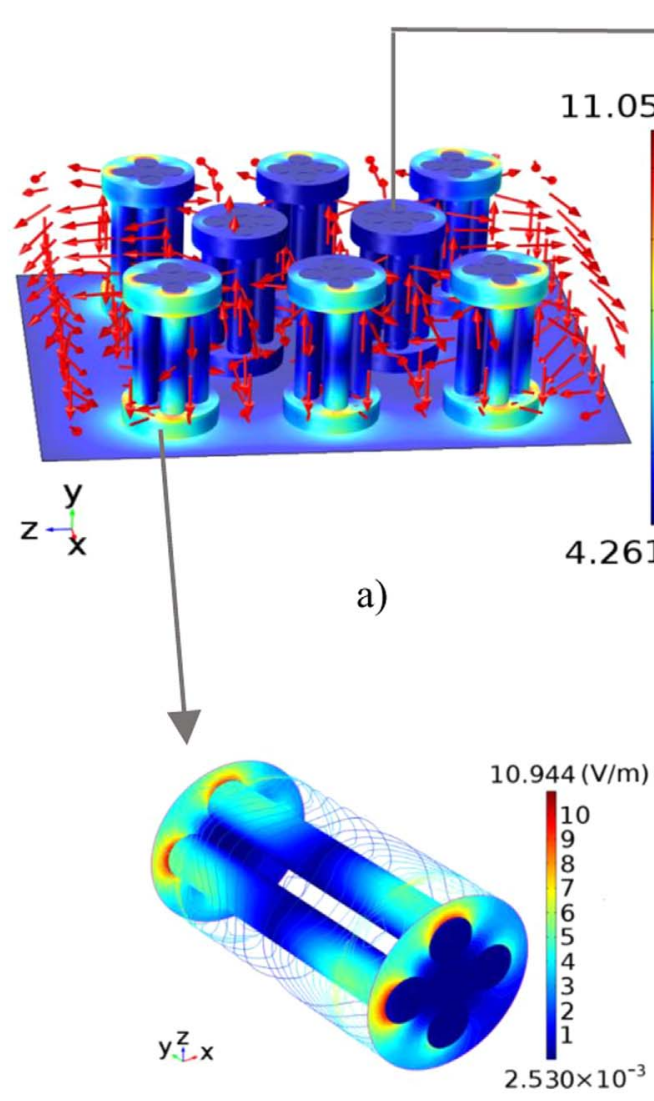

c)
$\sigma(\mathrm{T}, \mathrm{S}=0)=10^{-4}\left[8 \times 10^{-5} \times \mathrm{T}^{2}-0.0015 \mathrm{~T}+0.0387\right]$

In Eqs. (9) through (13), the coefficients are [23]: $a_{0}=5.7230$, $a_{1}=2.2379 \times 10^{-2}, a_{2}=-7.1237 \times 10^{-4}, a_{3}=5.0478, a_{4}=-7.0315 \times 10^{-2}$, $a_{5}=6.0059 \times 10^{-4}, a_{6}=3.6143, a_{7}=2.8841 \times 10^{-2}, a_{8}=1.3652 \times 10^{-1}$, $a_{9}=1.3825 \times 10^{-3}, a_{10}=2.4166 \times 10^{-4}$.

After rewriting Eq. (8) to separate the real and the imaginary parts, it can be written as Eq. (16).

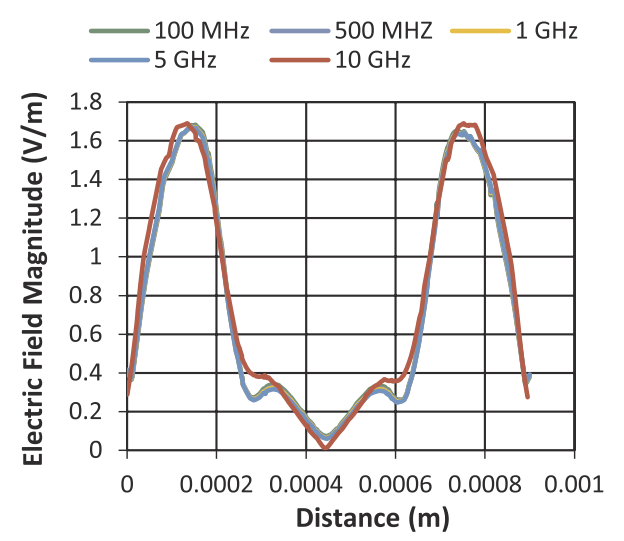

a)

$$
\begin{aligned}
\varepsilon_{r}(\mathrm{~T}, \mathrm{~S})= & \left\{\frac{\mathrm{v}_{1}(\mathrm{~T}, \mathrm{~S})^{2}\left(\varepsilon_{\mathrm{s}}(\mathrm{T}, \mathrm{S})-\varepsilon_{1}(\mathrm{~T}, \mathrm{~S})\right)}{\mathrm{v}_{1}(\mathrm{~T}, \mathrm{~S})^{2}+v^{2}}\right. \\
& \left.+\frac{\mathrm{v}_{2}(\mathrm{~T}, \mathrm{~S})^{2}\left(\varepsilon_{1}(\mathrm{~T}, \mathrm{~S})-\varepsilon_{\infty}(\mathrm{T}, \mathrm{S})\right)}{\mathrm{v}_{2}(\mathrm{~T}, \mathrm{~S})^{2}+v^{2}}+\varepsilon_{\infty}(\mathrm{T}, \mathrm{S})\right\} \\
& -i\left\{\frac{v_{1}(\mathrm{~T}, \mathrm{~S}) \times \mathrm{v} \times\left(\varepsilon_{\mathrm{s}}(\mathrm{T}, \mathrm{S})-\varepsilon_{1}(\mathrm{~T}, \mathrm{~S})\right)}{\mathrm{v}_{1}(\mathrm{~T}, \mathrm{~S})^{2}+v^{2}}\right. \\
& \left.-\frac{\mathrm{v}_{2}(\mathrm{~T}, \mathrm{~S}) \times \mathrm{v} \times\left(\varepsilon_{1}(\mathrm{~T}, \mathrm{~S})-\varepsilon_{\infty}(\mathrm{T}, \mathrm{S})\right)}{v_{2}(\mathrm{~T}, \mathrm{~S})^{2}+v^{2}}-\frac{\sigma(\mathrm{T}, \mathrm{S})}{2 \pi \varepsilon_{0} \mathrm{v}}\right\}
\end{aligned}
$$

Fig. 11 shows real part of relative electric permittivity versus frequency calculated from Eq. (16) [23] (filled squares) and from a

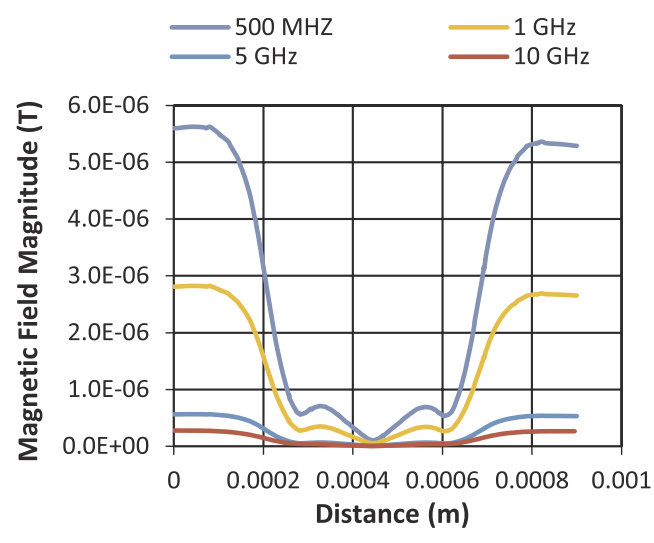

b)

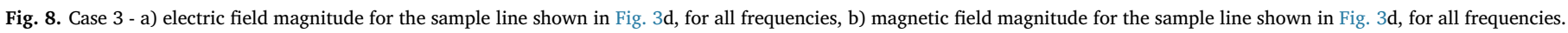




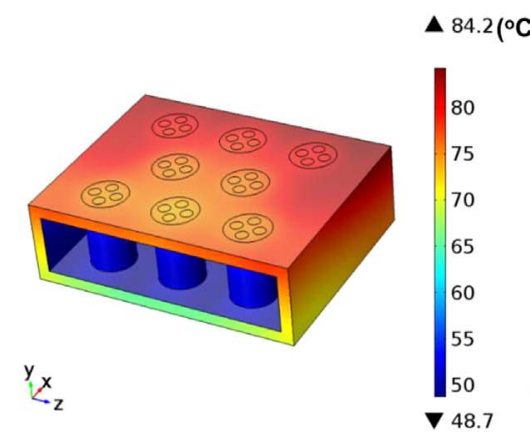

a)

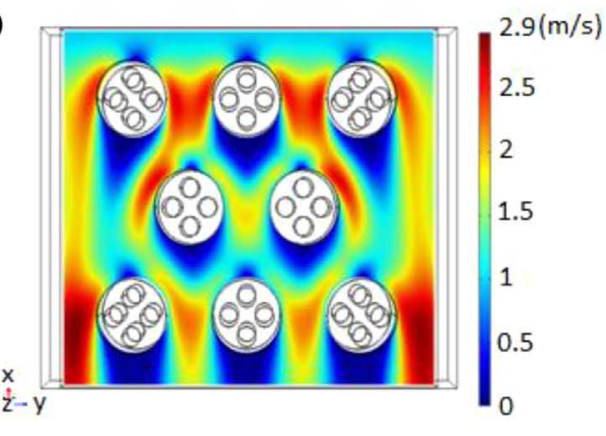

b)

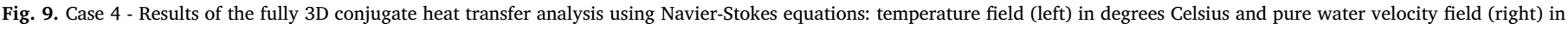
meters per second.

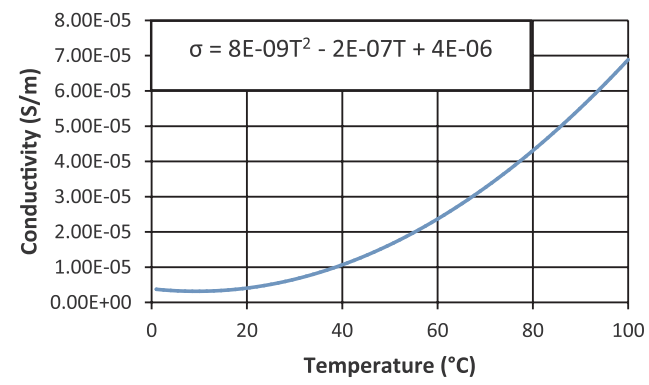

Fig. 10. Electric conductivity, $\sigma$, of pure water as a function of temperature [22]. This figure and equation were obtained by defining a polynomial curve in Excel.

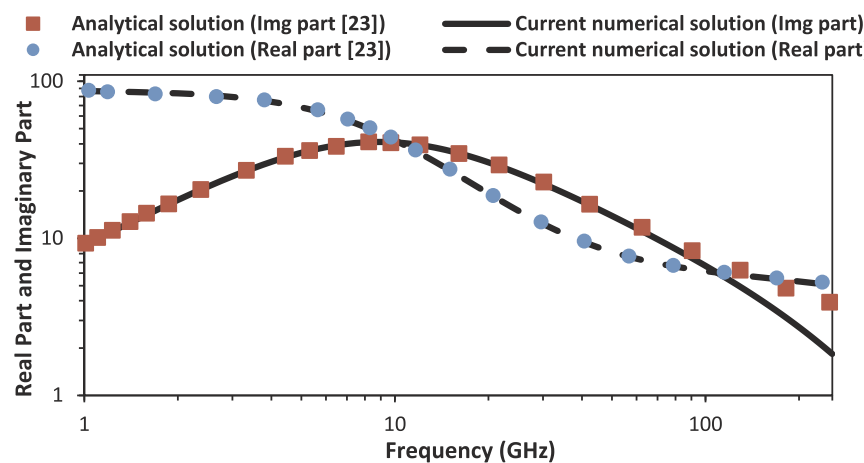

Fig. 11. Real part (squares) and absolute value of the imaginary part (circles) of relative electric permittivity as a function of frequency of the electric field applied in pure water at $0{ }^{\circ} \mathrm{C}$ : symbols represent analytical solutions of Meissner and Wentz [23] given by Eq. (16), while solid curves represent the values after incorporated them via Excel into COMSOL software [16].

few values that were interpolted by the COMSOL software [16]. According to this figure, our current numerical method can predict real part of relative permittivity with negligible error. By increasing frequency of the electric field, real part of relative electric permittivity decreases remarkably. In other word, as frequency increases from 1 to $256 \mathrm{GHz}$, real part of relative permittivity changes from 86.897 to 5.0292 , respectively. Although these are results for a constant temperature $\mathrm{T}=0{ }^{\circ} \mathrm{C}$, it can be inferred that increasing frequency can decrease the relative permittivity noticeably.

Fig. 11 also shows magnitude of the imaginary part of relative electric permittivity versus frequency calculated from Eq. (16) [23] (filled circles) and from a few values that were interpolted by the COMSOL software [16]. As this figure shows, when frequency is $1 \mathrm{GHz}$ the value of relative permittivity is 9.0994 . When frequency is $9 \mathrm{GHz}$, absolute value for imaginary part of relative permittivity reaches its highest value which is 41.038. After reaching frequency of $9 \mathrm{GHz}$, absolute value for imaginary part of relative permittivity follows a downward trend and reaches its lowest value which is 1.8372 when frequency is $256 \mathrm{GHz}$. It can also be observed from Fig. 11 that current numerical procedure is able to predict imaginary part of relative permittivity that is in good agreement with the analytical result [23]. As Fig. 11 shows, when frequency is higher than $100 \mathrm{GHz}$, the current numerical procedure underestimate the imaginary part of relative permittivity. Hence, it can be inferred from Fig. 11 that current numerical procedure is able to predict real part and imaginary part of relative permittivity quite accurately, especially when frequency of the electric field is lower than $100 \mathrm{GHz}$.

Fig. 12a shows real part of relative electric permittivity versus temperature for pure water at four distinct frequencies. At low frequency $(1 \mathrm{GHz})$, real part of relative electric permittivity decreases linearly as temperature increases. At higher frequencies, as temperature increases, real part of relative electric permittivity first increases and then decreases linearly. For example, when frequency is $10 \mathrm{GHz}$, real part of the relative electric permittivity has its lowest value (47) at $4{ }^{\circ} \mathrm{C}$ and reaches its highest value $(64.811)$ at $39^{\circ} \mathrm{C}$. Between $30{ }^{\circ} \mathrm{C}$ and $60{ }^{\circ} \mathrm{C}$, which is the range of local temperatures of the cooling water in the array of micro pin-fins (TSVs) shown in Fig. 9, the real part of relative permittivity is higher than 62 and relatively uniform.

Fig. 12b shows imaginary part of relative electric permittivity versus temperature for pure water at four distinct frequencies. As this figure shows, in case of each of the four frequencies that were used in the current simulation, imaginary part of the relative electric permittivity starts with a high absolute value and it decreases as temperature increases. For example, although absolute value of imaginary part of relative electric permittivity is high (40.5) when frequency is $10 \mathrm{GHz}$ at $4{ }^{\circ} \mathrm{C}$, it reduces to a low value of 15 when temperature is $70^{\circ} \mathrm{C}$.

Thus, absolute values of the imaginary part of the relative electric permittivity are less than approximately one third of the real part of the relative electric permittivity when temperature of the pure water is between $30^{\circ} \mathrm{C}$ and $60^{\circ} \mathrm{C}$ which is the average temperature range of the water cooling an array of micro pin-fins (TSV). Consequently, an approximate increase of the magnitude of the relative electric permittivity is

$\varepsilon_{r} \cong \varepsilon_{r \text { Real }} \sqrt{1+(1 / 3)^{2}}=1.054 \varepsilon_{r \text { Real }}$

In other word, using a combination of real and imaginary part of relative electric permittivity can increase the magnitude of relative permittivity by approximately $5 \%$ in pure water in temperature interval between $30^{\circ} \mathrm{C}$ and $60^{\circ} \mathrm{C}$, which is not significant (Fig. 13). This observation was then further confirmed by using the actual temperature-dependent and frequency-dependent physical properties of pure water in the conjugate forced cooling simulation of the micro array of pin fins (Fig. 9).

After obtaining data from Matlab code, output data were defined via interpolation function inside COMSOL [16] to run simulation by using the value of real part of relative permittivity only, besides using values of real part together with imaginary part of relative permittivity 


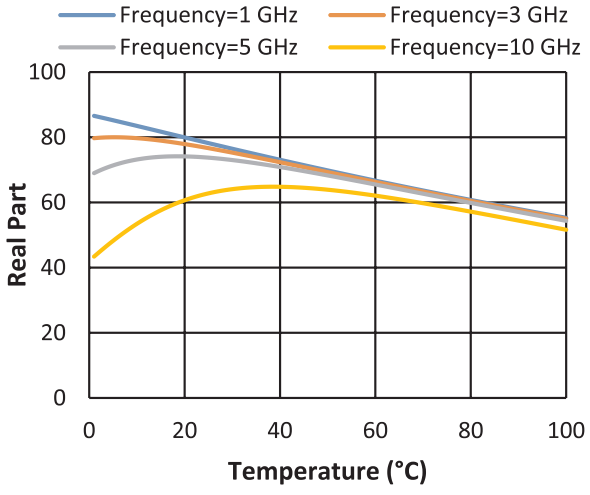

a)

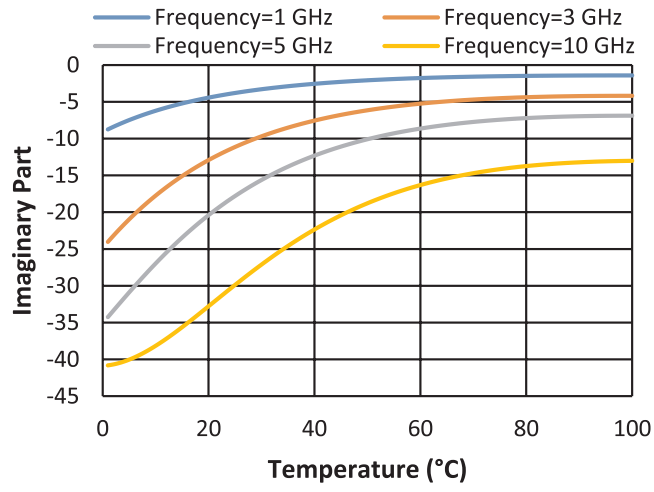

b)

Fig. 12. Real part (a) and imaginary part (b) of relative electric permittivity as a functions of temperature of pure water at four distinct frequencies of the electric field.

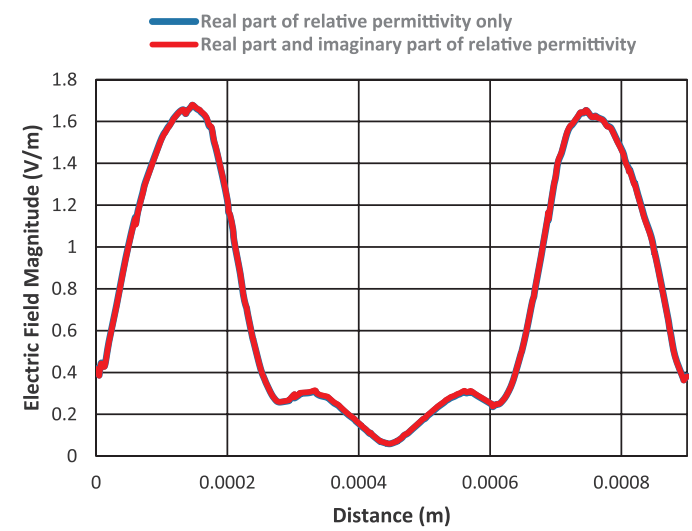

Fig. 13. Electric field magnitude at frequency $f=10 \mathrm{GHz}$ in pure water for the sample line by considering: a) real part of relative electric permittivity only (gray line), and b) considering both real and imaginary parts of relative electric permittivity. Simulation performed in COMSOL [16].

(magnitude) for making comparison to see whether imaginary part of relative permittivity can significantly change electric field magnitude. As Fig. 13 shows, using imaginary part together with real part of relative permittivity cannot change electric field magnitude significantly when compared to the calculations where imaginary part of the electric permittivity was neglected. The average difference between these two results is trivial (1\%) in the conjugate cooling simulations of a the micro array of pin fins (Fig. 9). The reason for this is the high temperature of water in the current simulation. Water temperature at inlet is $30^{\circ} \mathrm{C}$ and it rapidly increases to over $50^{\circ} \mathrm{C}$ as it moves past hot top wall and TSVs (Fig. 9). As Fig. 12b shows, at low temperatures magnitude of the imaginary part of relative electric permittivity of water is comparable in comparison with the real part of relative electric permittivity. Therefore, using imaginary part of relative electric permittivity might be necessary only when local temperature of the water is relatively low (lower than $15^{\circ} \mathrm{C}$ ).

In Fig. 14, the electric and magnetic field results for $1 \mathrm{GHz}$ are shown for Case 4 . The inlet temperature of water was $30^{\circ} \mathrm{C}$. Although direct comparisons between these results and previous results including stagnant fluid (Figs. 3, 5 and 7) would not be fair due to different frequencies used, the same distribution pattern in terms of direction of electric field can be observed in Fig. 14a as in the previous cases.

The frequency difference showed more effect on the magnetic field distribution which has clearly changed (Fig. 14d) as compared with the cases when the cooling fluid was stagnant. The second reason for such variations in the magnetic field pattern could be due to the non-uniform distribution of relative magnetic permeability resulting from the nonuniform temperature distribution in the flowing water. It can be seen that the maximum electric field magnitude in this case was $14.5 \mathrm{~V} \mathrm{~m}^{-1}$.
It can be seen in Fig. 14b and Fig. 14c that the electric field magnitude is very large at the ends of the TSVs.

In order to make the comparisons among the four test cases more meaningful and usable for real size cooling configurations, TSVs in this paper were classified into two groups; a) side (corner) TSVs which included 6 TSVs adjacent to walls, and b) middle TSV which included the two middle TSVs. Fig. 15 shows the normalized values of the maximum and average of the electric field magnitudes for the side and middle TSVs at each frequency. The stagnant water value at $100 \mathrm{MHz}$ was used as the normalization reference.

The maximum value of electric field increased as the fluid was changed from air to R13a and then to water. The maximum electric field magnitude for stagnant water was approximately 1.9 times larger than in case of air and 1.5 times larger than in case of R134a liquid. The average value of electric field for stagnant water was approximately 4 times larger than for air and 2.3 times larger than for R134a. This is mainly due to very high relative electric permittivity of water compared to air and R134a liquid. Insignificant reductions of the average and maximum values of the electric field magnitudes at $1 \mathrm{GHz}$ were observed using flowing water compared to stagnant water for the side (corner) TSVs. Also, it can be observed in Fig. 15 that by increasing the frequency, the maximum and average electric field magnitudes decreased. The maximum and average electric field magnitudes when using R134a were 1.2 and 1.7 times larger than the maximum and average electric field magnitudes when using air, respectively.

Smaller electric field magnitude values can be observed for the middle TSVs compared to the corner TSVs. However, the ratio of the $\left|E_{\max }\right|$ of water over $\left|E_{\max }\right|$ of air was 1.9 , and $\left|E_{\max }\right|$ of water over $\left|E_{\max }\right|$ of R134a was 1.5, which were almost the same as at the corner TSVs. The ratio of average value of electric fields in case of water over air was 4.2 which was slightly more than at the corner TSVs. The ratio of this parameter for water over R134a was 2.4, which was slightly larger than at the corner TSVs. The flowing water reduced the $\left|\mathrm{E}_{\mathrm{ave}}\right|$ by 1.2 times compared to stagnant water, which is more than at corner TSVs that showed negligible variations. This is mainly because of the effect of the non-uniform distribution of relative permittivity resulting from the non-uniform temperature distribution due to the moving water. The ratios of maximum and average electric field magnitudes for R134a over air (notice that both of these fluids were analysed without fluid motion) remained the same at the corner TSVs which were 1.2 and 1.7 , respectively.

Fig. 15 shows normalized values in which all of the actual values were divided with their highest values.

The normalized maximum and average of magnetic field magnitudes are shown in Fig. 16. Again, these result have been normalized using the stagnant water value at $100 \mathrm{MHz}$. For each coolant, by increasing the frequency, the magnetic field magnitudes decreased significantly. This was also shown in Figs. $4 \mathrm{~d}, 6 \mathrm{~d}$ and $8 \mathrm{~d}$ and it was explained by the "skin effect". As this figure demonstrates, for lower 


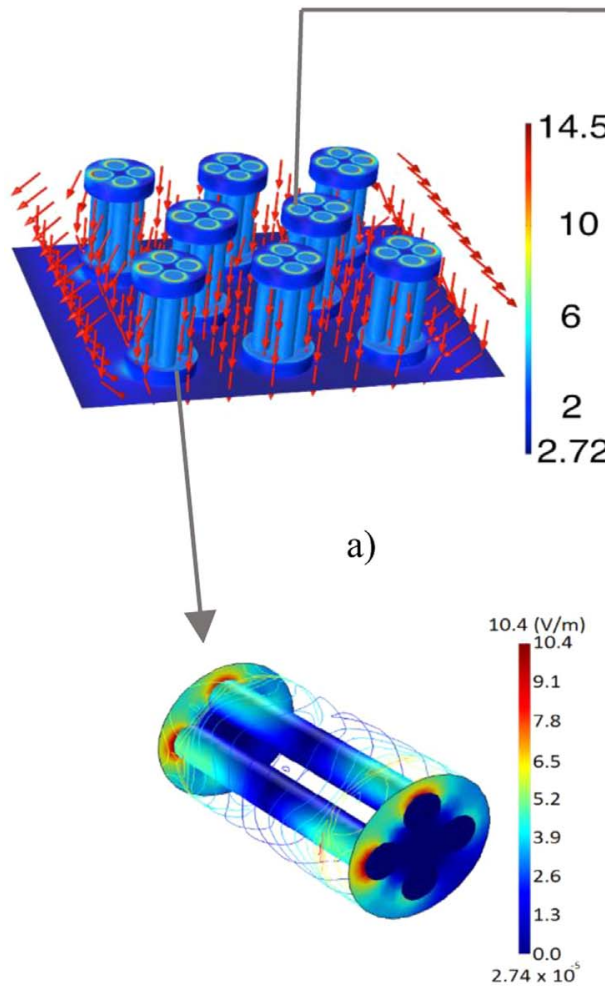

c)

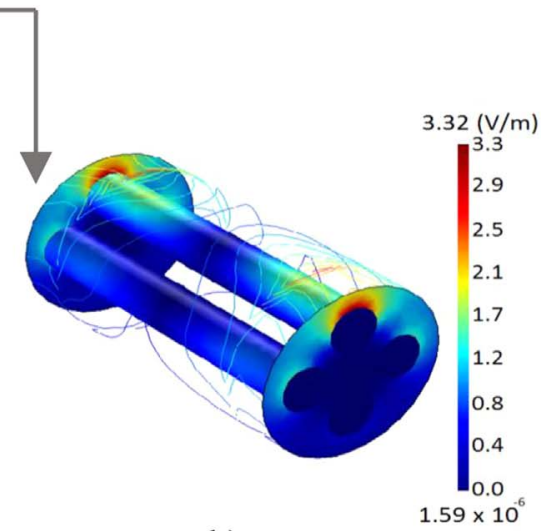

b)

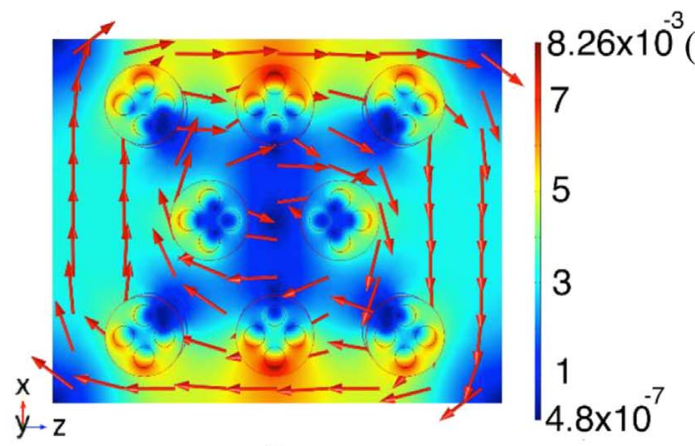

d)

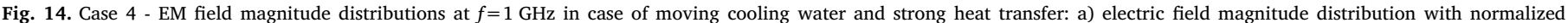
directional arrows for all TSVs, b) one of the middle TSVs, c) one of the corner TSVs, and d) magnetic field magnitude distribution with normalized directional arrows (top view).

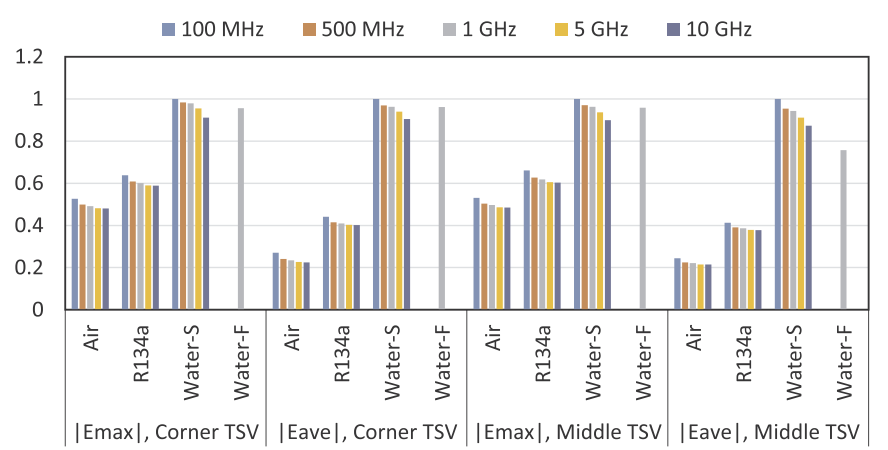

Fig. 15. The normalized maximum and average of electric field magnitudes for the corner and middle TSVs (Water-S is stagnant water and Water-F is flowing water). The stagnant water at $100 \mathrm{MHz}$ was used as the normalization reference. $\mathrm{E}_{\max }$ value for the stagnant water at $100 \mathrm{GHz}$ was $12.08146 \mathrm{~V} \mathrm{~m}^{-1}$.

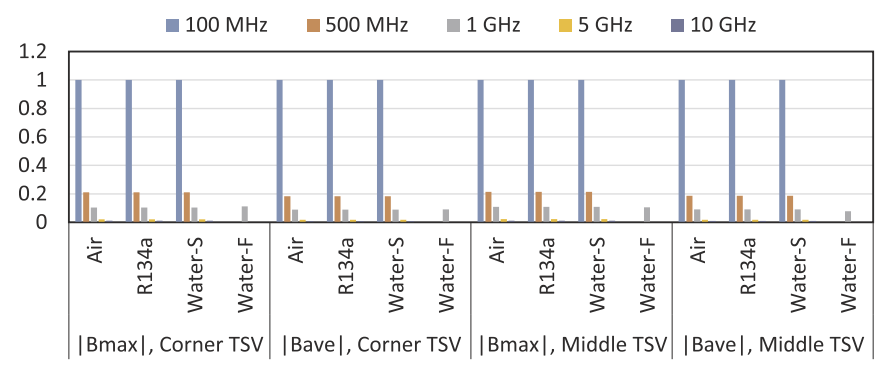

Fig. 16. The normalized maximum and average of magnetic field magnitudes for the corner and middle TSVs. The stagnant water at $100 \mathrm{MHz}$ was used as the normalization reference. (Water-S is stagnant water and Water-F is flowing water). The stagnant water at $100 \mathrm{MHz}$ was used as the normalization reference. $\mathrm{B}_{\max }$ value for the stagnant water at $100 \mathrm{GHz}$ was $1.44 \mathrm{E}-04 \mathrm{~V} \mathrm{~m}^{-1}$ frequencies, magnetic field magnitudes for all three fluids are the same. By increasing the frequency, an insignificant increment in magnetic field values for water can be observed compared to air and R134a liquid. The average and maximum values of the magnetic field magnitudes at $1 \mathrm{GHz}$ were slightly increased in case of flowing water compared to stagnant water. It can also be observed that the variation patterns for both maximum and average magnetic field magnitudes in the middle TSVs were the same as at the corner TSVs.

\section{Conclusions}

The effects of three different cooling fluids (air, R134a refrigerant liquid and water) on the magnetic and electric fields of arrays of micro pin-fins having integrated TSVs were studied at five different frequencies $(100 \mathrm{MHz}, 500 \mathrm{MHz}, 1 \mathrm{GHz}, 5 \mathrm{GHz}$ and $10 \mathrm{GHz})$. A uniform high intensity heat flux was applied to the cooling configuration and fully three-dimensional conjugate heat transfer analysis was performed. Both stagnant and flowing conditions were used for water as the working fluid.

One of the findings of this study is that the effect of different coolants on the magnetic field is very small and becomes negligible as frequency of the applied field increases and temperature range between $30{ }^{\circ} \mathrm{C}$ and $60{ }^{\circ} \mathrm{C}$. The middle TSVs showed smaller values for the magnetic and electric field magnitudes compared to the corner TSVs, due to suppression of the electromagnetic field near the centre.

The second finding of this study is that the coolant can have significant impact on the electric field of such micro-electronic packages. For instance, water showed significant effects on the electric field compared to air and R134a refrigerant, which is because of its high relative permittivity. For the corner TSVs, the average electric field magnitude using stagnant water cooling was nearly 4 times larger than in air cooling and 2.3 times larger than in R134 cooling. These values for the middle TSVs were 4.2 and 2.4. 
The moving fluid condition with strong heat transfer slightly reduced the coolant fluid impact on the electric field compared to the stationary fluid condition. The maximum and average electric field magnitudes of R134a in the corner TSVs were 1.2 and 1.7 times larger than the maximum and average electric field magnitudes in case of air, respectively. These ratios remained the same for the middle TSVs. COMSOL results of the fully 3D conjugate heat transfer/electromagneto-hydrodynamics analysis of flowing water cooling of an array of micro pin-fin TSVs including combined real and imaginary part of the relative electric permittivity at higher frequencies and water temperature range between $30{ }^{\circ} \mathrm{C}$ and $60{ }^{\circ} \mathrm{C}$ has shown negligible difference compared with the results when only real part of the relative electric permittivity was used. Imaginary part of relative electric permittivity might be necessary to include when local temperature of the water is relatively low (lower than $15{ }^{\circ} \mathrm{C}$ ). A recommendation for future research is to expand this effort include oxide and depletion regions on TSVs/vias to improve the accuracy of the simulations. In addition, RLGC network model and S-parameter can be utilized to further investigate the signal characterization of 3D signal through Silicon vias.

\section{Acknowledgements}

The authors are grateful for the partial financial support of this research provided by DARPA grant HR0011-14-1-0002 via GaTech grant RE314-G1 in the framework of ICECool project under supervision of Dr. Avram Bar-Cohen. They are also grateful for the partial financial support provided by DOE/NETL grant DE-FE0023114. This research was also partially supported by the Naval Surface Warfare Center, Panama City Division, Florida under the supervision of Dr. Frank J. Crosby and facilitated by Dr. Quyen Huynh via TriCircle Company. The second author is grateful for the financial support of Florida International University Presidential Fellowship. Authors are especially grateful for the help and constructive suggestions provided by the anonymous reviewer of this paper.

\section{References}

[1] A. Bar-Cohen, Gen-3 thermal management technology: role of microchannels and nanostructures in an embedded cooling paradigm, J. Nanotechnol. Eng. Med. 4 (2) (2013) 020907.

[2] V. Sahu, Y.K. Joshi, A.G. Fedorov, Experimental investigation of hotspot removal using superlattice cooler, Thermal and Thermomechanical Phenomena in Electronic Systems (ITherm), in: Proceedings of the 12th IEEE Intersociety Conference, Las Vegas, Nevada, 2010.

[3] J.-Q. Lu, 3-D hyperintegration and packaging technologies for micro-nano systems, Proc. IEEE 97 (1) (2009) 18-30.

[4] A. Dembla, Y. Zhang, M.S. Bakir, Fine pitch TSV integration in silicon micropin-fin heat sinks for 3D ICs, in: Proceedings of the Interconnect Technology Conference
(IITC), IEEE International, 2012, pp. 1-3. 〈http://doi.org/10.1109/IITC.2012. 6251587>.

[5] A. Abdoli, G. Jimenez, G.S. Dulikravich, Thermo-fluid analysis of micro pin-fin array cooling configurations for high heat fluxes with a hot spot, Int. J. Therm. Sci. 90 (2015) 290-297.

[6] S.R. Reddy, A. Abdoli, G.S. Dulikravich, C.C. Pacheco, G. Vasquez, R. Jha, Multiobjective optimization of micro pin-fin arrangements for cooling of high heat flux electronics with a hot spot, paperInterPackICNMM2015-48242, in: Proceedings of the ASME 12th International Conference on Nanochannels, Microchannels and Minichannels, InterPACK2015, San Francisco, California, USA, June 5-9, 2015.

[7] I. Savidis, S. Kose, E.G. Friedman, Power noise in TSV-based 3-D integrated circuits, IEEE J. Solid-State Circuits 48 (2) (2013) 587-597.

[8] H. He, J.Q. Lu, Compact models of voltage drops in power delivery network for TSV-based three-dimensional integration, IEEE Electron Device Lett. 34 (3) (2013) 438-440.

[9] J. Xie, M. Swaminathan, Electrical-thermal co-simulation of 3D integrated systems with micro-fluidic cooling and Joule heating effects, IEEE Trans. Compon. Packag. Manuf. 1 (2) (2011) 234-246.

[10] H. He, Z. Xu, X.-.X. Gu, J.-.Q. Lu, Power delivery modeling for 3D systems with nonuniform TSV distribution, in: Proceedings of Electric Components and Technology Conference, January 2013.

[11] J. Xie, B. Xie, M. Swaminathan, Electrical-thermal modeling of through-silicon via (TSV) arrays in interposer, Int. J. Numer. Model.: Electron. Netw. Devices Fields 26 (6) (2013) 545-559.

[12] B.H. Dennis, G.S. Dulikravich, S. Yoshimura, Control of flow separation over a circular cylinder with electro-magnetic fields: Numerical simulation, mini-symposium on Computational Electro-magneto-hydro-dynamics, 6th World Congress on Computational Mechanics, Beijing, China, Sept. 5-10, 2004; also Chapter 12 in Computing the Future IV: Frontiers of Computational Fluid Dynamics - 2006 (eds.), Caughey, D. A. and Hafez, M. M.), World Scientific, Singapore, 2006, pp. 265-284.

[13] H.-.J. Ko, G.S. Dulikravich, A fully non-linear model of electro-magneto-hydrodynamics, Symposium on Rheology and Fluid Mechanics ofNon-Linear Materials (eds.), D. A. Siginer and D. De Kee, Anaheim, CA, Nov. 15-20, 1998, ASME FEDVol. 246/MD-Vol. 81, pp. 173-182; also in Int. J. Non-Linear Mech., vol. 35(4), 2000, pp. 709-719.

[14] H.-J. Ko, G.S. Dulikravich, Non-reflective boundary conditions for a consistent twodimensional planar electro-magneto-hydrodynamic flow model, Int. J. Non-Linear Mech. 36 (1) (2000) 155-163.

[15] H.-.J. Ko, G.S. Dulikravich, Non-reflective boundary conditions for a consistent model of axisymmetric electro-magneto-hydrodynamic flows, Symposium on Rheology and Fluid Mechanics of Nonlinear Materials, ASME IMECE'99 (ed.) D. A. Siginer, Nashville, TN, November 14-19, 1999, ASME FED-Vol. 249, pp. 97-104; also in International Journal of Nonlinear Sciences and Numerical Simulation, vol. 1(4), December 2000, pp. 247-256.

[16] COMSOL Multiphysics ${ }^{\circledast}$. (C) 1997-2014 COMSOL, 2014. 〈http://www.comsol. $\mathrm{com} />$.

[17] S. Feja, Measurement of electrical properties of refrigerants and refrigerant-oil mixtures, Int. J. Refrig. 35 (2012) 137.

[18] ASHRAE ASHRAE, Fundamentals Handbook (SI) - Refrigerants, Chapter 19, 2001.

[19] DuPont DuPont, Suva 134a Refrigerant - Physical Properties of HFC-134a, Table 2, pp. 3, 2001.

[20] J.B. Hasted, Liquid water: dielectric properties, in: Water a Comprehensive Treatise, vol. 1 (eds.) F. Franks, Plenum Press, New York, 1972, pp. 255-309.

[21] R. Buchner, J. Barthel, J. Stauber, The dielectric relaxation of water between $0{ }^{\circ} \mathrm{C}$ and $35^{\circ} \mathrm{C}$, Chem. Phys. Lett. 306 (1999) 57-63.

[22] 〈http://www.analyticexpert.com/2011/03/temperature-compensation-algorithmsfor-conductivity/ $\rangle$.

[23] T. Meissner, F.J. Wentz, The complex dielectric constant of pure and sea water from microwave sattelite observations, IEEE Trans. Geosci. Remote Sens. 42 (9) (2004) 1836-1849. 